\title{
HETEROSIS, MATERNAL, DAN INDIVIDUAL EFFECT PADA HIBRIDA ANTARA IKAN MAS RAJADANU, MAJALAYA, SUBANG, DAN KUNINGAN
}

\author{
Muhammad Hunaina Fariduddin Ath- thar, Vitas Atmadi Prakoso, \\ Estu Nugroho, dan Rudhy Gustiano \\ Balai Riset Perikanan Budidaya Air Tawar \\ Jl. Sempur No. 1, Bogor 16154 \\ E-mail: mhfariduddinaththar@yahoo.co.id
}

(Naskah diterima: 5 Agustus 2011; Disetujui publikasi: 28 November 2011)

\begin{abstract}
ABSTRAK
Ikan mas merupakan salah satu komoditas potensial untuk mendukung pencapaian peningkatan produksi perikanan budidaya nasional sebanyak 353\% pada 2014. Ikan mas yang digunakan selama ini hanya mengandalkan strain lokal yang sudah mengalami penurunan kualitas. Hibridisasi merupakan salah satu cara untuk menghasilkan ikan unggul. Hibridisasi dilakukan secara resiprok dari 4 strain ikan mas Rajadanu, Subang, Majalaya dan Kuningan sehingga didapatkan 16 kandidat strain baru. Parameter yang digunakan sebagai evaluasi hibrida ini adalah sintasan dan keragaan pertumbuhan. Nilai maternal effect, individual effect dan heterosis dari sintasan dan keragaan pertumbuhan ikan hasil hibrid menjadi acuan untuk pemilihan kandidat hibrid yang terbaik. Untuk parameter pertumbuhan, nilai maternal effect tertinggi didapat dari ikan lokal Subang dan nilai individual effect tertinggi pada Majalaya. Sedangkan untuk parameter sintasan, nilai maternal effect tertinggi didapat dari ikan lokal Kuningan dan nilai individual effect tertinggi pada Rajadanu. Dari skoring nilai heterosis didapatkan hasil bahwa hibrida ikan lokal Kuningan dan Majalaya merupakan hibrida terbaik.
\end{abstract}

KATA KUNCl: ikan mas, hibridisasi, heterosis, maternal effect dan individual effect

ABSTRACT: Heterosis, maternal, and individual effect on hybridized carp of Rajadanu, Subang, Majalaya, and Kuningan. By: Muhammad Hunaina Fariduddin Ath-thar, Vitas Atmadi Prakoso, Estu Nugroho, and Rudhy Gustiano

Carp has been selected by Indonesian Goverment as one of several commercially potential fishes to be developed in order to be the largest aquaculture producing countries by the end of 2014. However, until now, its aquaculture development is far from satisfaction due to heavily rely on local strains which have had a decline in quality. Overcoming that problem, hybridization is seen as an alternative to produce superior growth carp. Hybridization was carried out by reciprocal crosses of four strains of Rajadanu, Subang, Majalaya and Kuningan carp to obtain 16 new strain candidates. Afterward, maternal effect, individual effect and heterosis from growth test and survival rate were measured to find out the best hybrid candidate. Based on growth rate, Subang strain has highest maternal effect and Majalaya strain has the highest individual effect. But from survival rate parameter, Kuningan strain was 
detected to have the highest maternal effect and Rajadanu was highest on individual effet. By considering heterosis scoring, hybrid from Kuningan strain and Majalaya strain was arguably the best hybrid candidate.

\section{KEYWORDS: carps, hybridization, heterosis, maternal effect and individual effect}

\section{PENDAHULUAN}

Peningkatan produksi perikanan sebesar 353\% pada 2014 harus didukung oleh berbagai aspek perikanan budidaya. Salah satu aspek perikanan budidaya yang ikut berpengaruh terhadap peningkatan produksi tersebut adalah aspek genetik dan pengembangbiakan ikan. Pemuliaan ikan merupakan aspek dari genetik yang bisa memberikan pengaruh terhadap peningkatan dengan pembentukan strain unggul. Salah satu cara pemuliaan konvensional yang tidak membutuhkan waktu yang lama, terutama untuk ikan mas adalah dengan hibridisasi. Menurut Gjedrem (1993), hibridisasi adalah hibridisasi antara dua individu yang berbeda untuk mendapatkan keturunan yang lebih baik. Selain itu, hibridisasi adalah memanfaatkan sifat heterosis karena sifat dominan dan heterozigot pada banyak lokus (Tave, 1995).

Peningkatan produksi tidak hanya dihasilkan oleh perkawinan satu strain tetapi juga dihasilkan dari hibridisasi, hibridisasi antar strain (Lutz, 2001). Selain mengambil keuntungan dari heterosis, hibridisasi kadangkadang dilakukan hanya untuk menggabungkan sifat spesifik spesies terkait. Tujuan lain dari usaha tersebut adalah untuk produksi stok steril fungsional, baik untuk budidaya komersial atau introduksi langsung ke alam. Sejumlah studi telah dilakukan dengan beberapa spesies akuatik untuk mencapai tujuan tersebut.

Beberapa keuntungan hibridisasi menurut Lutz (2001) adalah dapat meningkatkan proporsi heterozigositas gen dan menurunkan proporsi homozigositas gen serta jika bahan dasar hibridisasi jauh kekerabatannya, maka keturunannya menampilkan keragaan yang lebih baik jika dibandingkan tetua/ induknya. Hibridisasi dirasa cukup efektif untuk ikan mas dibandingkan seleksi famili karena membutuhkan waktu yang lebih singkat tanpa mengesampingkan teknologi transgenesis yang sedang dikembangkan di Indonesia.
Beberapa penelitian tentang hibridisasi ikan mas telah dilakukan di Vietnam (Thien, 1993) yang menghasilkan ikan mas hibrid dengan sintasan, laju pertumbuhan dan penampilan lebih baik serta di China (Wu, 1993) yang menghasilkan ikan mas hibrid dengan pertumbuhan lebih cepat dibanding tetuanya dan ikan mas di alam.

Perbaikan mutu benih ikan air tawar di Indonesia merupakan program sistem pembenihan nasional yang melibatkan petani pembenih untuk memproduksi benih sebar hasil dari induk pokok varietas unggul. Induk pokok diperoleh dari induk dasar yang berasal dari induk penjenis. Induk penjenis tersebut mempunyai sifat keunggulan yang utamanya sifat reproduksi dan pertumbuhan yang diperoleh hasil pemuliaan (seleksi) dan hasil hibridisasi. Saat ini pada ikan air tawar khususnya ikan mas tidak terdapat varietas unggul sehingga penggunaan varietas lokal seperti Sinyonya dan Majalaya sejak tahun 1980-an serta galur lokal lainnya masih dipertahankan bagi petani pembenih.

Besarnya kontribusi ketersediaan induk unggul guna perbaikan mutu benih melalui perbaikan mutu genetik ikan air tawar khususnya program seleksi dan hibridisasi menempatkan varietas unggul ikan merupakan komoditas strategis. Dengan hibridisasi diharapkan terdapat peningkatan mutu genetik dari hybride vigoure $(\mathrm{H})$ yang langsung dapat dirasakan dalam budidaya pembesaran oleh pembudidaya. Sebagai langkah awal program hibridisasi ikan mas, pada penelitian ini akan dilakukan uji awal pertumbuhan terhadap ikan hasil hibridisasi 4 strain ikan mas (Rajadanu, Subang, Majalaya, dan Kuningan).

\section{BAHAN DAN METODE}

Penelitian ini dilakukan di Instalasi Riset Plasma Nutfah Cijeruk, BRPBAT Bogor. Hibridisasi dilakukan secara resiprokal terhadap 4 strain ikan mas yang kekerabatan genetiknya jauh yaitu ikan mas strain Rajadanu, Subang, Majalaya, dan Kuningan. Hibridisasi 
dilakukan secara serentak dengan pemijahan secara buatan. Hasil hibridisasi kemudian ditetaskan pada happa berbeda yang telah diberi tanda sesuai hasil hibridisasi. Setelah umur 1 minggu benih hasil hibridisasi dipindahkan ke kolam berukuran $4 \mathrm{~m} \times 4 \mathrm{~m}$ dengan kepadatan $1000 / \mathrm{m}^{2}$ kemudian dilakukan uji pertumbuhan selama 1 bulan pemeliharaan. Parameter yang digunakan dalam uji pertumbuhan ini adalah pertumbuhan panjang dan sintasan. Setelah diperoleh data pertumbuhan panjang dan sintasan kemudian dilakukan analisis dan skoring terhadap nilai heterosis dari pertumbuhan bobot dan sintasan. Selain itu, juga dilakukan analisis terhadap efek matenal dan efek individu terhadap hibrida ikan mas.

\section{HASIL DAN BAHASAN}

Berdasarkan penghitungan heterosis dari parameter sintasan dan pertumbuhan, maka diperoleh hasil seperti yang tertera pada Gambar 1.

Dari Gambar 1 dapat diketahui bahwa hasil bahwa hibrida ikan lokal Kuningan dan Majalaya merupakan hibrida yang terbaik. Ekspresi heterosis, di mana keturunan individu yang tidak berhubungan menunjukkan peningkatan keragaan, adalah dasar bagi kebanyakan upaya hibridisasi dan perkawinan silang. Penurunan akibat inbreeding sebaliknya menjelaskan penurunan dalam keragaan yang dihasilkan dari hibridisasi individu yang sekerabat. Karena kedua faktor ini merupakan manifestasi dari efek dominasi genetik, maka setiap diskusi tentang salah satu faktor tersebut biasanya harus juga merujuk kepada yang lainnya juga. Wohlfarth (1993) memiliki temuan yang terkait dengan heterosis pada ikan mas. Dia mendefinisikan heterosis sebagai pertumbuhan yang melebihi dari pertumbuhan tercepat strain parental, dan menunjukkan bahwa heterosis untuk pertumbuhan dalam spesies ini adalah umum, tetapi belum tentu semuanya seperti itu. Pada kondisi-kondisi tertentu, seperti suhu air yang lebih hangat, dan fase hidup tertentu seperti periode pertumbuhan tahun pertama ekspresi atau penghitungan heterosis pada ikan mas akan lebih mudah daripada yang lain. Karena heterosis dihitung berdasarkan pada cross-bycross dan trait-by-trait, serta tergantung pada interaksi genom induknya, sebagaimana kemungkinan beberapa hibridisasi tidak menunjukkan heterosis.

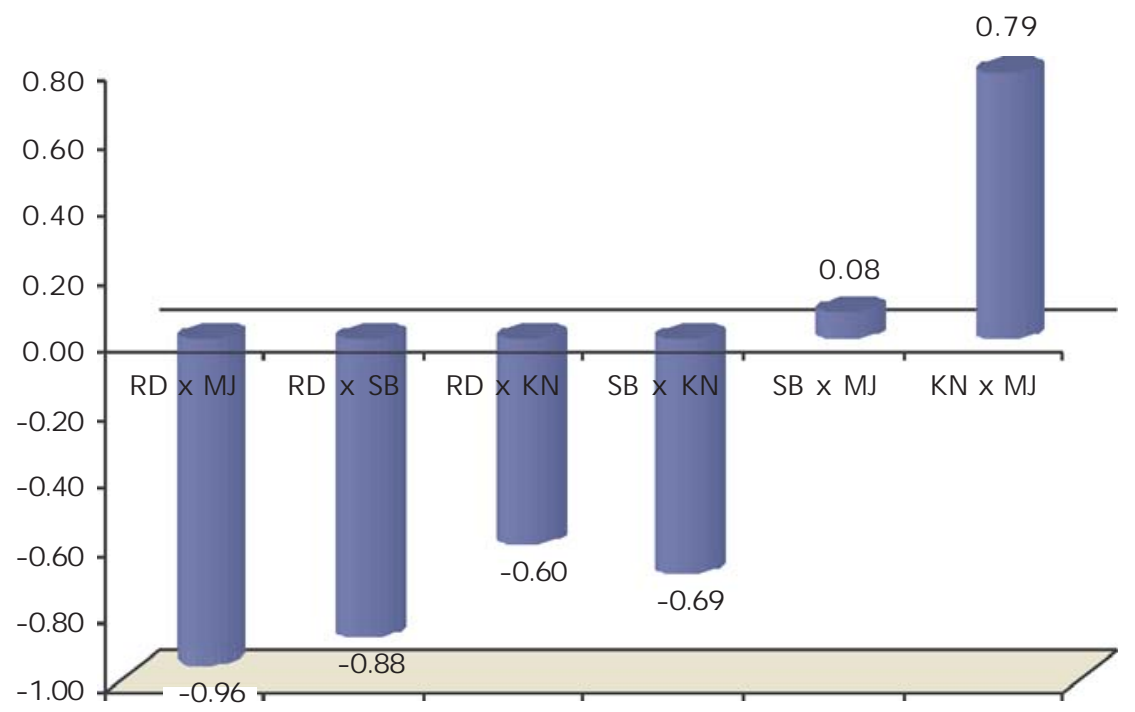

Gambar 1. Hasil skoring heterosis dari parameter sintasan dan pertumbuhan pada hibrida dari empat strain ikan mas (Rajadanu (RD), Majalaya (MJ), Subang (SB), dan Kuningan (KN))

Figure 1. Heterosis scoring result of survival and crowth rate of hybrids from four carp strains (Rajadanu (RD), Majalaya (MJ), Subang (SB), and Kuningan $(K N)$ ) 


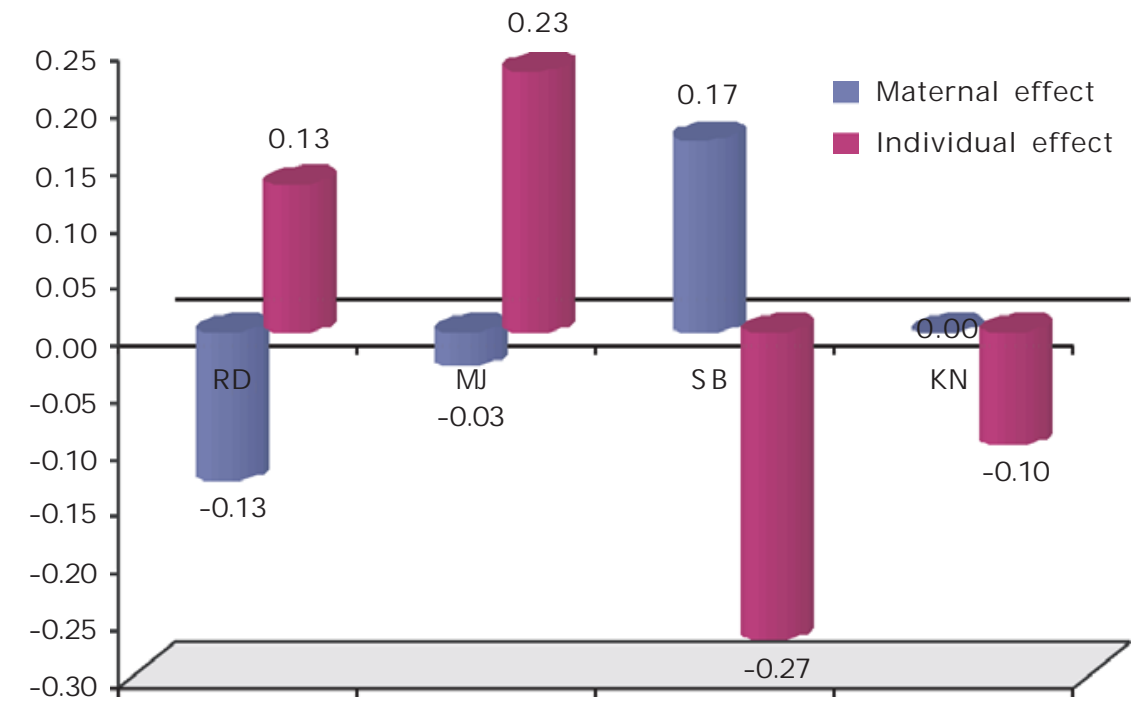

Gambar 2. Maternal effect dan individual effect dari parameter pertumbuhan pada empat strain ikan mas (Rajadanu (RD), Majalaya (MJ), Subang (SB), dan Kuningan (KN))

Figure 2. Maternal effect and individual effect based on growth rate of four carp strains (Rajadanu (RD), Majalaya (MJ), Subang (SB), and Kuningan $(K N)$ )

Kemudian dari parameter pertumbuhan, maka diperoleh hasil seperti yang tertera pada Gambar 2. Dari Gambar 2 dapat diketahui bahwa untuk parameter pertumbuhan, nilai maternal effect tertinggi didapat dari ikan mas strain lokal Subang dan nilai individual effect tertinggi terdapat pada ikan mas strain Majalaya. Dari hasil ini dapat diartikan bahwa induk betina dari strain lokal Subang memberikan pengaruh yang paling tinggi terhadap pertumbuhan benih ikan mas hasil hibridisasi. Sedangkan jika dilihat dari segi individunya, strain Majalaya memberikan pengaruh yang tertinggi terhadap pertumbuhan benih ikan mas hasil hibridisasi.

Maternal effect adalah pengaruh dari ukuran, umur, dan kondisi induk betina yang berpengaruh terhadap telur dan pertumbuhan serta karakteristik embrio setelah pembuahan (Kirpichnikov, 1981). Falconer \& Mackay (1996) mendefinisikan maternal effect sebagai pengaruh induk betina terhadap karakter fenotip keturunannya. Maternal effect menjadi berpengaruh karena gamet jantan lebih kecil daripada gamet betina (Heath et al., 1999). Pada ikan, maternal effect lebih berpotensi penting terhadap fase awal kehidupan (larva sampai dengan benih) (Chambers \& Leggett, 1996).

Maternal effect ini dapat memperlihatkan heterosis. Pada 2 jenis ikan nila, Tave et al. (1990) menunjukkan bahwa heterosis maternal membuat kontribusi yang substansial terhadap pertumbuhan. F2 (F1 dengan F1) dan hasil perkawinan backcross ( $\mathrm{F} 1$ dengan parent) lebih besar daripada parent F1 mereka karena maternal effect dari betina F1 yang dihasilkan dari hibridisasi asli. Terkadang, pengaruh maternal effect mungkin kecil tetapi tetap cukup mendalam dari segi perilaku di bawah kondisi budidaya. Setelah melakukan penelitian dengan menggunakan beberapa jenis nila hibrida, Toguyeni et al. (1997) menggambarkan pola pewarisan maternalnya dalam perilakunya yang agresif.

Untuk parameter sintasan, nilai maternal effect tertinggi didapat dari ikan mas strain lokal Kuningan dan nilai individual effect tertinggi pada ikan mas strain Rajadanu (Gambar 3). Dari hasil ini dapat diartikan bahwa induk betina dari strain Kuningan memberikan pengaruh yang paling tinggi terhadap sintasan benih ikan mas hasil hibridisasi. Sedangkan 


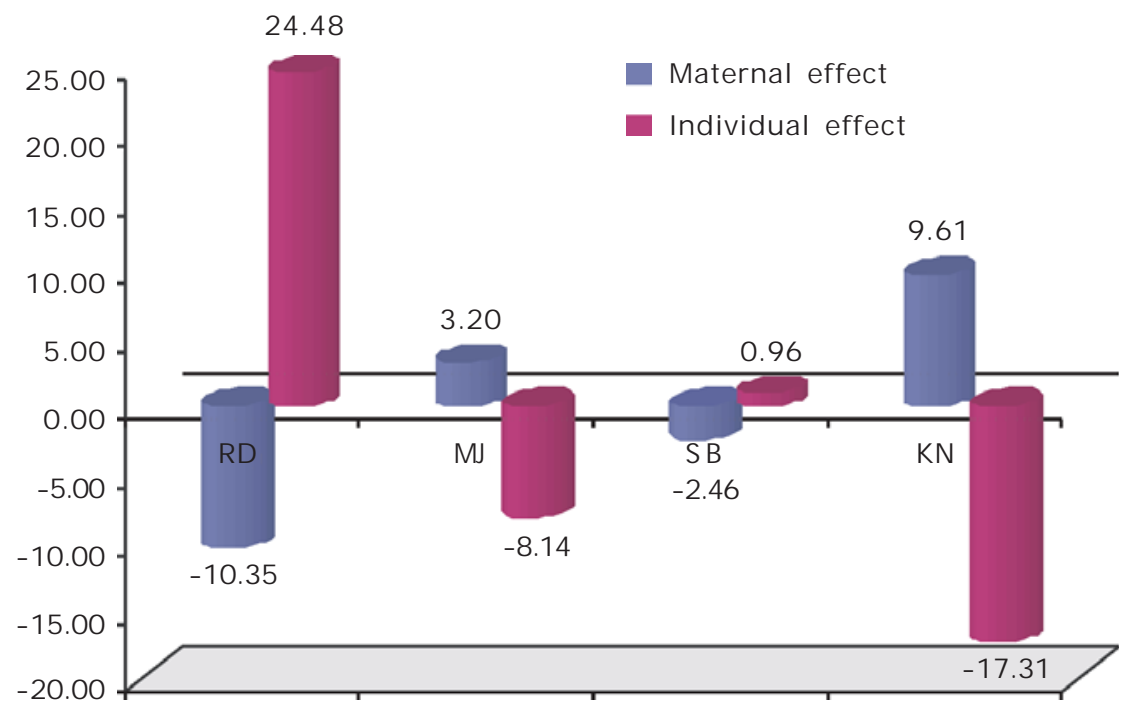

Gambar 3. Maternal effect dan individual effect dari parameter sintasan pada empat strain ikan mas (Rajadanu (RD), Majalaya (MJ), Subang (SB), dan Kuningan (KN))

Figure 3. Maternal effect and individual effect based on survival rate of four carp strains (Rajadanu (RD), Majalaya (MJ), Subang (SB), and Kuningan $(K N))$

jika dilihat dari segi individunya, strain Rajadanu memberikan pengaruh tertinggi terhadap sintasan benih ikan mas hasil hibridisasi.

\section{KESIMPULAN}

Dari penelitian ini dapat disimpulkan bahwa untuk parameter pertumbuhan, nilai maternal effect tertinggi didapat dari ikan lokal Subang dan nilai individual effect tertinggi pada Majalaya. Sedangkan untuk parameter sintasan, nilai maternal effect tertinggi didapat dari ikan lokal Kuningan dan nilai individual effect tertinggi pada Rajadanu. Dari skoring nilai heterosis didapatkan hasil bahwa hibrida ikan lokal Kuningan dan Majalaya merupakan hibrida terbaik.

\section{DAFTAR ACUAN}

Chambers, R.C. \& Leggett, W.C. 1996. Maternal influences on variation in egg sizes in temperate marine fishes. American Zoologist, 36: 180-196.

Falconer, D.S. \& Mackay, T.F.C. 1996. Introduction to Quantitative Genetics. Longman, Harlow, UK, 464 pp.
Gjedrem, T. 1993. International Selective Breeding Programs: Constraints and Future Prospect. In : Main K.L. and E. Reynolds. Selective Breeding of Fishes in Asia and The United States. Proceeding of A Workshop in Honolulu, Hawaii, May 3- 7, 1993, p.1823.

Heath, D.D., Fox, C.W., \& Heath, J.W. 1999. Maternal effects on offspring size: variation through early development of Chinook salmon. Evolution, 53: 1605-1611.

Kirpichnikov, V.S. 1981. Genetic Bases of Fish Selection. Springer Verlag, Berlin, 410 pp.

Lutz, C. Greg. 2001. Practical genetics for Aquaculture. Blackwell and sciences. UK.

Tave, D., Smitherman, R.O., Jayaprakas, V., \& Kuhlers, D.L. 1990. Estimates of additive genetic effects, maternal genetic effects, individual heterosis, maternal heterosis, and egg cytoplasmic effects for growth in Tilapia nilotica. Journal of the World Aquaculture Society, 21(Suppl., 4): 263-270.

Thien, T.M. 1993. A Review of the Fish Breeding Research and Practises in Indonesia. In : Main K.L. and E. Reynolds. Selective Breeding of Fishes in Asia and The United States. 
Proceeding of A Workshop in Honolulu, Hawaii, May 3- 7, 1993, p. 190- 197.

Toguyeni, A., Fauconneau, B., \& Melard, C. 1997. Sexual dimorphism studies in tilapias, using two pure species, Oreochromis niloticus and Sarotherodon melanotheron, and their intergeneric hybrids (O. niloticus $\times$ S. melanotheron and S. melanotheron $\times$ O. niloticus). In: Tilapia Aquaculture: Proceedings from the Fourth International Symposium on Tilapia in Aquaculture (ed. K. Fitzsimmons), NRAES- 106 Volume 1, Northeast Regional Agricultural Engineering Service, Ithaca, New York, p. 200-212.
Wohlfarth, G.W. 1993. Heterosis for growth rate in common carp. Aquaculture, 113 (Suppl. 1-2): 31-46.

Wu, C. 1993. A Review of Traditional Fish Selective Breeding Research and Practises in China with Emphasis on the use of Genetic Markers. In : Main K.L. and E. Reynolds. Selective Breeding of Fishes in Asia and The United States. Proceeding of A Workshop in Honolulu, Hawaii, May 3- 7, 1993. p. 206- 213. 